\title{
Metabotropic Glutamate Receptor-Mediated Hippocampal Phosphoinositide Turnover Is Blunted in Spatial Learning-Impaired Aged Rats
}

\author{
Michelle M. Nicolle, ${ }^{1}$ Paul J. Colombo, ${ }^{2}$ Michela Gallagher, ${ }^{3}$ and Michael McKinney ${ }^{1}$ \\ ${ }^{1}$ Mayo Clinic, Department of Pharmacology, Jacksonville, Florida 32224, ${ }^{2}$ Tulane University, Department of Psychology, \\ New Orleans, Louisiana 70118, and 3Johns Hopkins University, Department of Psychology, Baltimore, Maryland 21218
}

\begin{abstract}
Maximal phosphoinositide (PI) turnover was examined in the hippocampus of young and aged Long-Evans rats that were behaviorally characterized for spatial learning in the Morris water maze. The type 1 metabotropic glutamate receptor (mGluR) agonist 1S,3R ACPD was used to stimulate PI turnover and to determine the $E_{\text {MAX }}$ for each rat. Protein levels in hippocampus for type $1 \mathrm{mGluRs}, \mathrm{G} \alpha \mathrm{q} 11$, and phospholipase $\mathrm{C} \beta-1$ (PLC $\beta$-1) were also measured by quantitative Western blotting. The results show that $\mathrm{PI}$ turnover mediated by the mGluRs was blunted in the aged rats. The magnitude of the decrement in PI turnover was also significantly correlated with age-related spatial memory decline. The decrease in mGluR-mediated PI turnover occurred without changes in the protein level of either the mGluRs or the G-protein coupled to those receptors, G $\alpha$ q11. A significant decrease in the immunoreactivity of PLC $\beta-1$, how-
\end{abstract}

Pharmacological studies of receptor systems can provide insight into the functional integrity of aged hippocampal neurons by probing the intracellular components of signal transduction ("the effector"). Further insight can be obtained if such studies examine multiple neurotransmitter receptors that are coupled to the same signal transduction system. Phosphoinositide (PI) signal transduction is coupled to both type I metabotropic glutamate receptors (mGluR-1 and mGluR-5) and the muscarinic acetylcholine receptor subtype M1 (m1 and m3) (Fisher and Bartus, 1985; Gu and Wolfe, 1985; McKinney et al., 1991; Schoepp, 1994). We previously reported that maximal muscarinic receptor-mediated PI turnover is blunted in the hippocampus of aged Long-Evans rats, an effect that was correlated with poorer spatial learning and that occurred without a reduction in the amount of $\mathrm{m} 1$ and $\mathrm{m} 3$ protein or in the pharmacologically defined number of spare receptors (Chouinard et al., 1995). Those findings suggested that a defect lies in the effector system of the PI signaling pathway, i.e., G-protein or beyond.

The type $1 \mathrm{mGluRs}$ share the same effector components of the PI signal transduction pathway as the muscarinic receptors (Fisher and Bartus, 1985; Gu and Wolfe, 1985; McKinney et al., 1991;

\footnotetext{
Received June 10, 1999; revised Aug. 12, 1999; accepted Aug. 12, 1999.

This work was supported by National Institute on Aging (NIA) Fellowship AG05804 to M.N., Research Scientist Award K05-MH01149 to M.G., and NIA Grant AG09973 to M.M. and M.G. We thank Dr. Barry Wolfe, Edina Gianapulous, and Rob McMahon for technical assistance.

This paper is in memory of Dr. Michael Bunsey.

Correspondence should be addressed to Dr. Michelle M. Nicolle, Department of Pharmacology, Mayo Clinic, 310 Birdsall Building, 4500 San Pablo Road, Jacksonville, FL 32224. E-mail: nicolle.michelle@mayo.edu.

Copyright (C) 1999 Society for Neuroscience 0270-6474/99/199604-07\$05.00/0
}

ever, was observed in the hippocampus of aged rats; PLC $\beta-1$ immunoreactivity was significantly correlated with spatial learning only when the young and aged rats were considered together. The decrement in mGluR-mediated signal transduction in the hippocampus that is related to cognitive impairment in aging may be attributable, at least in part, to a deficiency in the enzyme PLC $\beta-1$. That deficiency may also contribute to a blunted response in muscarinic stimulation of hippocampal PI turnover that we previously found in this same study population. An age-related alteration in this signal transduction system may provide a functional basis for cognitive decline independent of any loss of neurons in the hippocampus.

Key words: phosphoinositide; hippocampus; aging; spatial memory; metabotropic glutamate receptor; Gaq11; phospholipase $C \beta-1$.
Schoepp, 1994). The G-protein effector for both mGluR and muscarinic PI-coupled receptors is the pertussis toxin-insensitive G-protein $\alpha$ subunit $\mathrm{q} / 11$, which activates the enzyme phospholipase C $\beta$-1 (PLC $\beta$-1) (Smrcka et al., 1991; Taylor et al., 1991; Berstein et al., 1992). These receptors are particularly relevant in the study of the hippocampus because they are located postsynaptically on the granule cells of the dentate gyrus and pyramidal neurons of Ammon's horn (Lujan et al., 1996; Rouse and Levey, 1996), which do not undergo neurodegeneration in normal aging in rats with deficits in hippocampal-dependent learning (Rapp and Gallagher, 1996; Rasmussen et al., 1996). However, many studies suggest that receptor function is altered during aging in these hippocampal neurons. In the context of the current study, electrophysiological experiments have shown a diminished postsynaptic response to muscarinic cholinergic stimulation in all subfields of the hippocampal formation (Shen and Barnes, 1996). A number of studies have also shown that CA1 neurons in aged rats are less plastic and less able to reliably encode information than the neurons in their young counterparts (Barnes et al., 1997; Shen et al., 1997; Tanila et al., 1997a,b). Stimulation of mGluRs with their agonist provides a pharmacological approach for further assessing postsynaptic function of neurons in the aged hippocampus.

The current study characterized the nature of the age-related deficit in PI turnover by extending the investigation to the mGluRs and to elements of the effector system. To determine whether functional changes were caused by alterations at the receptor or the effector level, we included an assessment of hippocampal mGluR-1, mGluR-5, G $\alpha \mathrm{q} 11$, and PLC $\beta-1$ protein using quantitative Western blotting. For these studies, protein 
was obtained from the hippocampi from separate sets of young and aged Long-Evans rats, with the identical behavioral characterization for hippocampal-dependent spatial cognition.

\section{MATERIALS AND METHODS}

Subjects. Animals used in this study were male Long-Evans rats obtained pathogen-free from Charles River Laboratories (Raleigh, NC). They were kept in the University of North Carolina or the Johns Hopkins University Psychology Department vivarium for a minimum of 1 month before behavioral testing. Rats were singly housed in an environment that was climate-controlled at $25^{\circ} \mathrm{C}$ and maintained on a $12 \mathrm{hr}$ light/dark cycle (lights on at 7 A.M.). Food and water were provided ad libitum. Routine exams throughout the experiment, as well as necropsies at the time of killing, were performed to assess the health of the subjects. All rats included in these experiments were judged to be healthy and free from any evidence of pathologies such as pituitary tumors and renal dysfunction. "Young" rats were 6 months of age, and the "aged" rats were 26-27 months of age.

For the PI turnover study, 10 young and 15 aged male Long-Evans rats served as subjects. One week after behavioral testing, rats in that study were shipped to Mayo Clinic Jacksonville, housed in its vivarium, and maintained under the same environmental conditions described above. Rats were acclimated to the new facility for 1 week before the PI turnover assays were begun. Two other sets of rats were used for studies of protein levels; 8 young and 16 aged rats were used for the quantification of mGluR-1 and mGluR-5, and 12 young and 25 aged rats were used for the quantification of PLC $\beta-1$ and G $\alpha q 11$. Rats used for the mGluR protein analyses were killed $\sim 1$ week after the completion of behavioral testing. Rats used for the PLC $\beta-1$ and G $\alpha \mathrm{q} 11$ protein analyses were killed within $1 \mathrm{hr}$ after behavioral testing. After they were killed, the hippocampi of all rats in the protein study were rapidly dissected and frozen at $-80^{\circ} \mathrm{C}$.

Behavioral testing. All rats received a standardized behavioral characterization for spatial learning in a water maze (Gallagher et al., 1993). The water maze is a circular tank (1.83 m diameter and $0.58 \mathrm{~m}$ height) with a retractable escape platform centered in one of the four maze quadrants. During testing, the tank was filled to a depth of $35.5 \mathrm{~cm}$ with $27^{\circ} \mathrm{C}$ water clouded by the addition of nontoxic white tempura paint $(150$ $\mathrm{ml}$ ). The top of the escape platform was submerged $2 \mathrm{~cm}$ below the water surface. Spatial cues were provided by black patterns affixed to white muslin curtains that surrounded the outside perimeter of the maze at a distance of $\sim 40 \mathrm{~cm}$. Sensorimotor ability was assessed by cue training to a visible black platform extending $2 \mathrm{~cm}$ above the water surface. Data were analyzed using a video tracking system (HVS Image Analyzing VP-112) and an IBM PC computer equipped with software developed for the water maze by Richard Baker (HVS Imaging, Hampton, UK).

During a period of $8 \mathrm{~d}$, in sessions consisting of three trials per day, the rats were trained to locate the camouflaged platform that remained in the same location throughout training. During a training trial, the animal was placed in the water at the perimeter of the pool and allowed $90 \mathrm{sec}$ to locate the escape platform. If at the end of this interval the rat had failed to escape, it was placed onto the platform and allowed to remain there for $30 \mathrm{sec}$. The position of entry for the animal was varied at each trial. There was a $60 \mathrm{sec}$ intertrial interval. Every sixth trial consisted of a free swim ("probe trial") that served to assess the development of a spatially localized search for the escape platform. During probe trials the rat was allowed to swim a total of $30 \mathrm{sec}$ with the escape platform retracted to the bottom of the pool and unavailable for escape. After $30 \mathrm{sec}$ elapsed the platform was raised so that the rat could complete escape on the trial. A "learning index," which was generated from the proximity of the rat to the escape platform during probe trials [described in detail by Gallagher et al. (1993)], was used in correlation with the neurobiological data. This index is the sum of weighted proximity scores measured during probe trials. Low scores reflect search near the escape platform, whereas high scores reflect search farther away from the target. "Search error" during training trials refers to the deviation from a direct path to the platform and provided an additional measure for behavioral analysis [also described in detail by Gallagher et al. (1993)].

Cue training was conducted on the final day of behavioral testing. Cue training consisted of one session of six trials using a visible platform that was moved to different locations in the pool between trials. Each rat was given $30 \mathrm{sec}$ to reach the platform, and it remained on the platform briefly. Trials were separated by a $30 \mathrm{sec}$ intertrial interval. Cue training provided an assessment of sensorimotor and motivational factors that might influence performance in the spatial learning task.
The rats used for quantification of PLC $\beta-1$ and G $\alpha \mathrm{q} 11$ underwent an additional transfer training procedure in the water maze that consisted of a single session. Those rats were killed immediately after the completion of the transfer test session. The behavioral data from the transfer task has been reported previously (Colombo et al., 1997).

PI hydrolysis assay. The PI hydrolysis assay in hippocampal minces was the same as that used previously to examine muscarinic receptor stimulation of PI hydrolysis (Chouinard et al., 1995). This assay measures accumulated $\left[{ }^{3} \mathrm{H}\right] \mathrm{IP}-1$ released from $\left[{ }^{3} \mathrm{H}\right]$ inositol-labeled polyphosphoinositide stores. Rats were killed by decapitation, and their hippocampi were dissected on a cold plate, weighed, minced, and immediately placed in cold Puck's D1 solution. The mince was washed and resuspended in Krebs-Hensleit buffer containing (in $\mathrm{mm}$ ): $118 \mathrm{NaCl}, 25 \mathrm{NaHCO}_{3}, 4.7$ $\mathrm{KCl}, 1.2 \mathrm{MgSO}_{4} \cdot 7 \mathrm{H}_{2} \mathrm{O}, 1.3 \mathrm{CaCl}_{2} \cdot \mathrm{H}_{2} 0,1.2 \mathrm{KH}_{2} \mathrm{PO}_{4}, 12$ glucose, $\mathrm{pH} 7.4$, at $37^{\circ} \mathrm{C}$. The tissue was rejuvenated in Krebs buffer for $1 \mathrm{hr}$ at $37^{\circ} \mathrm{C}$ under $95 \% \mathrm{O}_{2} / 5 \% \mathrm{CO}_{2}$ in a Dubnoff hood with gentle shaking and two changes of buffer. The cells were metabolically labeled for $1 \mathrm{hr}$ with $60 \mu \mathrm{Ci}$ $\left[{ }^{3} \mathrm{H}\right]$ myo-inositol (DuPont NEN, Wilmington, DE; $25 \mathrm{Ci} / \mathrm{mmol}$ ) in Krebs buffer containing $10 \mathrm{~mm} \mathrm{LiCl}$ to prevent recycling of inositol. The tissue suspension was diluted to $10 \mathrm{mg}$ wet weight per milliliter and distributed to assay tubes $(2.4 \mathrm{mg} / \mathrm{tube} ; 300 \mu \mathrm{l}$ final volume) containing 1S,3R ACPD (Tocris Cookson, St. Louis, MO) in Krebs-LiCl. Tissue was incubated for $1 \mathrm{hr}$, and then the reaction was stopped with chloroform/methanol $(2: 1 \mathrm{v} / \mathrm{v})$. A [ $\left.{ }^{14} \mathrm{C}\right] \mathrm{IP}-1$ standard $\left(1000 \mathrm{dpm} / 1 \mathrm{ml} \mathrm{ddH_{2 } \mathrm { O } )}\right.$ was added to each tube to correct for column elution efficiency. Isolation of $\left[{ }^{3} \mathrm{H}\right] \mathrm{IP}-1$ and $\left[{ }^{14} \mathrm{C}\right] \mathrm{IP}-1$ was performed with Dowex resin columns and eluted with $3.5 \mathrm{M}$ formic acid. Basal $\left[{ }^{3} \mathrm{H}\right] \mathrm{IP}-1$ release (no agonist) was subtracted to express results as response to receptor stimulation.

Protein extraction and Western blotting. Proteins for the mGluR-1 and mGluR-5 analysis were extracted from previously frozen hippocampal tissue by homogenization in cold $10 \mathrm{~mm}$ Tris, $\mathrm{pH}$ 7.4, containing $1 \mathrm{~mm}$ EDTA with the use of a Tekmar Tissuemizer. Homogenates were centrifuged at $37,000 \times g$ for $10 \mathrm{~min}$, and the pellets (particulate fraction) were resuspended in $0.7 \%$ SDS and boiled for $5 \mathrm{~min}$. Aliquots were frozen at $-80^{\circ} \mathrm{C}$ until use.

Proteins for the analysis of G $\alpha \mathrm{q} 11$ and PLC $\beta-1$ were extracted in the following manner. Individual tissue samples were weighed and then homogenized in $5 \mathrm{vol}$ of ice-cold buffer containing $20 \mathrm{~mm}$ Tris- $\mathrm{HCl}, \mathrm{pH}$ 7.4, 0.25 m sucrose, 2 mm EDTA, 10 mm EGTA, 5 mm dithiothreitol, $0.234 \mathrm{~mm}$ leupeptin, and $1 \mathrm{~mm}$ PMSF. Homogenates were centrif uged at $100,000 \times g$ for $60 \mathrm{~min}$ at $4^{\circ} \mathrm{C}$. The supernatant was removed from each sample, and an aliquot was taken for determination of total protein concentration (Bradford, 1976). The pellets were resuspended in homogenizing buffer containing $0.1 \%$ Triton X-100, incubated for $60 \mathrm{~min}$ at $4^{\circ} \mathrm{C}$, and centrifuged at $100,000 \times g$ for $60 \mathrm{~min}$ at $4^{\circ} \mathrm{C}$. The supernatant was removed and vortexed, and an aliquot was taken for protein determination. The remaining supernatant was mixed (1:1) with $2 \times$ SDS sample buffer and heated as described above. The boiled samples, comprising the particulate fraction, were frozen at $-80^{\circ} \mathrm{C}$ until Western blot analysis. Previous studies have localized both G $\alpha \mathrm{q} 11$ and PLC $\beta-1$ to the particulate fraction (Kim et al., 1996; Kostenis et al., 1997). The protein concentration for all samples was determined using the bicinchoninic acid method (Pierce, Rockford, IL).

For the quantification of all proteins, each gel also contained a standard curve of known protein concentration. The source of protein for the standards was from the hippocampus of 3-month-old (mGluRs) or 6-month-old (PLC $\beta-1$ and G $\alpha \mathrm{q} 11$ ) naïve Long-Evans rats. For mGluR-1 and mGluR-5, the standard curve consisted of $0.5,1$, or $2 \mu \mathrm{g}$ protein. For G $\alpha \mathrm{q} 11$ and PLC $\beta-1$ the standard curve consisted of $5,10,15,20,30$, and $5,10,15,20$, and $25 \mu \mathrm{g}$ protein, respectively. An additional lane of the highest standard concentration was run on the opposite side of the gel to confirm uniformity in the protein transfer from the gel to the PVDF membrane. The samples were counterbalanced for age and learning index score. In replication runs, the sample position was altered to control for systematic bias in the blotting procedure. A minimum of four experiments was performed for the mGluR protein, and two were performed for $\mathrm{G} \alpha \mathrm{q} 11$ and PLC $\beta-1$.

Electrophoresis. Electrophoresis for mGluR-1 and mGluR-5 was performed using the NuPAGE system (Novex, San Diego, CA). One microgram of protein was loaded into each lane of a $10 \%$ Bis-Tris gel, and constant voltage $(200 \mathrm{~V})$ was applied for $60 \mathrm{~min}$ in 3 - $(N$-morpholino $)$ propane sulfonic acid- $0.5 \%$ SDS buffer. Proteins were transferred to PVDF membrane (Novex) in NuPage transfer buffer containing 10\% methanol for $2 \mathrm{hr}$ at $26 \mathrm{~V}$.

For the electrophoresis of $\mathrm{G} \alpha \mathrm{q} 11$ and PLC $\beta-1,10 \mu \mathrm{g}$ of protein was 
loaded into each lane of an $8 \%$ SDS-polyacrylamide gel and electrophoresed with constant current ( $30 \mathrm{~mA}$ per gel). After separation, the samples were transferred electrophoretically overnight at constant voltage $(15 \mathrm{~V})$ at $4^{\circ} \mathrm{C}$ to PVDF immobilon membranes (Millipore, Bedford, MA).

Immunoblotting. Membranes to be labeled with anti-mGluR-1 and mGluR-5 were blocked for $1 \mathrm{hr}$ in $10 \mathrm{~mm}$ PBS, pH 7.4, containing 3\% nonfat dry milk (PBS-milk). Membranes were then incubated for $1 \mathrm{hr}$ with either anti-mGluR-1 (1:500 dilution) or anti-mGluR-5 (1:5000 dilution) (Upstate Biotechnology, Lake Placid, NY) in PBS-milk. This was followed by three 5 min washes in $\mathrm{ddH}_{2} \mathrm{O}$. The blots were incubated for 30 min with HRP-conjugated anti-rabbit IgG (1:5000 dilution, Santa Cruz Biotechnology, Santa Cruz, CA) in PBS-milk. All blots were washed three times for $5 \mathrm{~min}$ in PBS-1\% BSA and two times in $\mathrm{ddH}_{2} \mathrm{O}$. Bound HRP was visualized by incubating the blots with chemiluminescent substrate (Pierce) and apposing the blots to ECL film (Amersham, Arlington Heights, IL).

Membranes to be blotted for PLC $\beta-1$ and G $\alpha \mathrm{q} 11$ were washed at room temperature three times for $5 \mathrm{~min}$ each in PBS, then three times for 15 min in a solution containing 5\% nonfat dry milk-0.03\% Tween-20-PBS (NFDM-Tween-PBS). Membranes were then incubated with antiPLC $\beta-1$ (1:5000) or anti-G $\alpha \mathrm{q} 11$ (1:1000) (Santa Cruz Biotechnology) for $2 \mathrm{hr}$ at room temperature in NFDM-Tween-PBS (Wetsel et al., 1992). Membranes were then washed as described above with PBS and NFDMTween-PBS and incubated with HRP-conjugated anti-rabbit IgG (1: $5000)$ in NFDM-Tween-PBS for $2 \mathrm{hr}$ at room temperature. The membranes were then washed extensively with a $0.1 \%$ Tween-20 PBS solution, and the signal was visualized as described above.

PI turnover data analysis. Triplicate assessments of receptor-mediated $\left[{ }^{3} \mathrm{H}\right] \mathrm{IP}-1$ release were averaged for each drug dose, and basal release was subtracted. The $1 \mathrm{~S}, 3 \mathrm{R}$ ACPD concentration-response assay was analyzed for $E_{\mathrm{MAx}}, \mathrm{EC}_{50}$, and Hill slope by fitting to a four-parameter sigmoidal dose-response function using GraphPad Prism software (San Diego, CA). The resulting individual values for $E_{\mathrm{MAX}}, \mathrm{EC}_{50}$, and slope were analyzed using a one-way ANOVA (age) and linear regression against the learning index (Statview, SAS Institute, Cary, NC). Regressions with the learning index were run for all animals together and for aged animals alone.

Western blot data analysis. Films were digitized, and the standard curves were used to extrapolate values for individual samples. Mean optical density was obtained for mGluR-1 and mGluR-5, and mean integrated density (optical density multiplied by the target area in pixels) was obtained for G $\alpha \mathrm{q} 11$ and PLC $\beta-1$. The two different measurements result in equivalent data $(r=0.99, p<0.0001$; data not shown). Western blot data were analyzed for each experiment using a one-way ANOVA (age). If an age effect was observed, the data were subsequently analyzed by linear regression with the learning index. Data are reported \pm SEM and reflect the average density across experiment replications.

\section{RESULTS}

\section{Behavioral characterization}

The aged rats used in the PI study performed more poorly on the spatial learning task than the young rats based on training trial and probe trial data. As shown in Figure $1 A$, aged rats did not differ from young rats on first exposure to the maze but were less proficient in locating the escape platform than the young rats over the course of training. This group difference was evident in a repeated-measures ANOVA (age $\times$ trial block) by a significant main effect of age $\left(F_{(1,23)}=17.32, p<0.01\right)$. Similar differences between young and aged groups were obtained for the rats used in the mGluR and G $\alpha$ q11/PLC $\beta-1$ studies $\left(F_{(1,22)}=19.2, p<0.01\right.$ and $F_{(1,36)}=21.32, p<0.01$, respectively; data not shown). Figure $1 B$ shows learning index scores for individual young and aged animals that were derived from interpolated probe trials. This measure for the development of an accurate search in the maze differed between the rats in the young and aged groups used for the PI turnover study, evidenced by significantly greater learning index scores for the aged rats (young $=189.73 \pm 11.96$ and aged $\left.=243.23 \pm 10.13 ; F_{(1,23)}=11.49, p<0.01\right)$. Similar results were obtained for the groups of rats used in the mGluR and

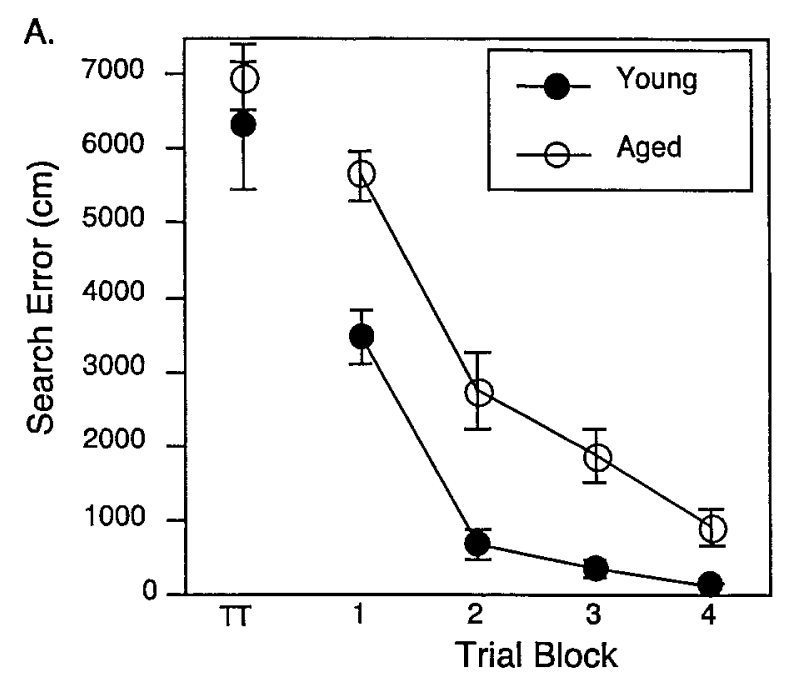

B.

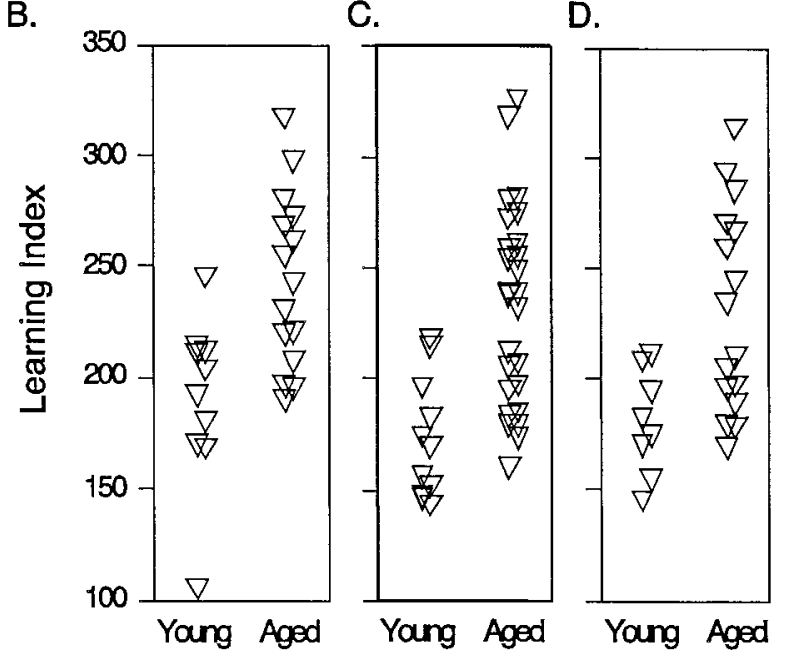

Figure 1. Assessment of spatial learning in young and aged rats. $A$, Mean search error $( \pm$ SEM $)$ to reach the escape platform across four blocks of five training trials during the spatial learning task. $T T$ indicates performance on the first training trial. $B$, Individual spatial learning scores calculated from probe trial data for rats used in the PI turnover study. A lower score represents a more accurate search. See Results for statistical analysis. $C$, Individual spatial learning scores for the subjects used in the immunoblotting of PLC $\beta-1$ and $\mathrm{G} \alpha \mathrm{q} 11 . D$, Individual spatial learning scores for the subjects used in the immunoblotting of mGluR-1 and mGluR-5.

$\mathrm{G} \alpha \mathrm{q} 11 / \mathrm{PLC} \beta-1$ studies $\left(F_{(1,22)}=8.5, p<0.01\right.$ and $F_{(1,36)}=19.41$, $p<0.01$, respectively) (Fig. $1 C, D$ ). In each set of rats, moreover, a similar distribution of learning index scores is evident, with some of the aged rats performing within the range of young rats and others falling outside the range of young rat performance. Rats in groups, regardless of age, had proficient sensorimotor ability in the swim task as indicated by equivalent latency scores for escape to the visible platform during cue training (PI turnover: young $=11.3 \pm 2.1 \mathrm{sec}$ and aged $=10.8 \pm 1.8 \mathrm{sec}$; mGluR: young $=7.99 \pm 1.95 \mathrm{sec}$ and aged $=6.34 \pm .59 \mathrm{sec} ; \mathrm{G} \alpha \mathrm{q} 11 /$ PLC $\beta-1$ : young $=11.77 \pm 1.1 \mathrm{sec}$ and aged $=10.62 \pm .98 \mathrm{sec})$.

\section{Receptor-mediated PI turnover in the hippocampus of young and aged rats}

As shown in Table 1, total cell associated radioactivity, basal $\left[{ }^{3} \mathrm{H}\right] \mathrm{IP}-1$ release, and the $\mathrm{EC}_{50}$ and Hill slope for mGluR- 
Table 1. Parameters of 1S,3R ACPD-stimulated PI turnover in young and aged rats \pm SEM

\begin{tabular}{lcc} 
& Young & Aged \\
\hline Cell-associated radioactivity $(\mathrm{dpm})$ & $8421 \pm 987$ & $7898 \pm 466$ \\
Basal $\left[{ }^{3} \mathrm{H}\right] \mathrm{IP} 1$ release $(\mathrm{dpm})$ & $497 \pm 33$ & $446 \pm 31$ \\
Log EC & $-5.17 \pm 0.10$ & $-5.11 \pm 0.08$ \\
Hill slope & $1.20 \pm 0.18$ & $1.78 \pm 0.36$ \\
1S,3R ACPD E & $562 \pm 27$ & $414 \pm 24$ \\
\hline
\end{tabular}

${ }^{a} \mathrm{dpm}$ with basal dpm subtracted.

${ }^{*} p<0.05$.

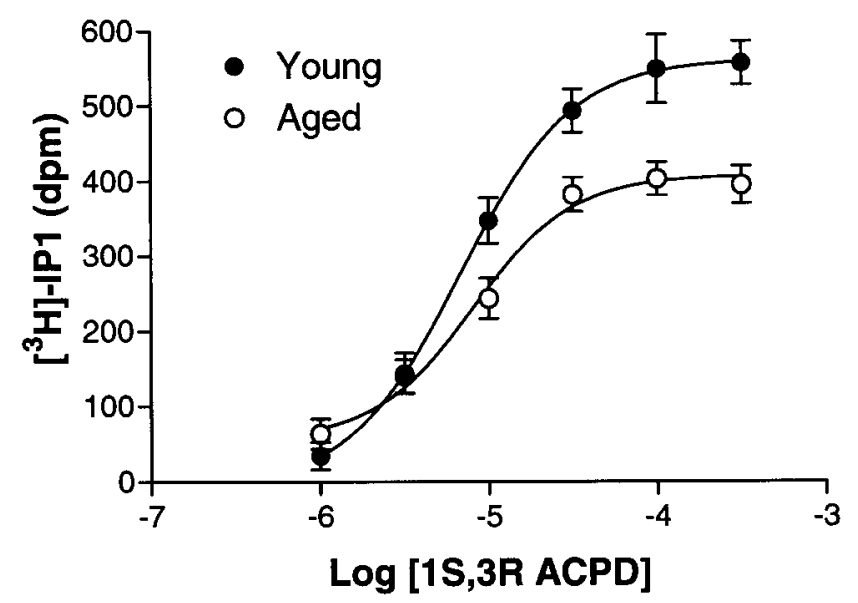

Figure 2. Type 1 mGluR-mediated PI turnover concentration-response curves in young and aged rats. The agonist was 1S,3R ACPD. The curves are fits of composites of data for young $(n=10)$ and aged $(n=15)$ rats.

mediated $\left[{ }^{3} \mathrm{H}\right] \mathrm{IP}-1$ release did not differ as a function of age. The maximal response $\left(E_{\mathrm{MAX}}\right)$ to stimulation with 1S,3R ACPD, however, was decreased in the aged hippocampus (Table 1). Figure 2 shows the composite 1S,3R ACPD dose-response curves for each age group. The 1S,3R ACPD $E_{\text {MAX }}$ values, analyzed in a one-factor ANOVA (age), were significantly blunted in the aged rats $\left(F_{(1,23)}=15.97, p<0.01\right)$.

The $E_{\mathrm{MAx}}$ for $1 \mathrm{~S}, 3 \mathrm{R}$ ACPD was analyzed using linear regression for a relationship with the spatial learning index. As shown in Figure 3, 1S,3R ACPD-mediated PI turnover was significantly correlated with the learning index when all animals were considered together $(r=-0.67, p<0.01)$. This relationship was also significant when the aged animals were considered alone $(r=$ $-0.53, p<0.05)$.

\section{MGluR-5 and mGluR-1 receptor protein}

Representative immunoblots for mGluR-5 and mGluR-1 are shown in Figure 4. Statistical analysis for the measures of these proteins using a one-way ANOVA showed no effect of age on either mGluR-1 or mGluR-5 (Table 2). For illustration purposes, those data are also shown plotted against the learning index (Fig. 4).

\section{$\mathrm{G} \alpha \mathrm{q} / 11$ and PLC $\beta-1$ protein}

Representative immunoblots for G $\alpha \mathrm{q} 11$ and particulate PLC $\beta-1$ are shown in Figure 5. Statistical analysis showed that there was no effect of age on G $\alpha$ q11 immunoreactivity levels (Table 2). However, there was a significant decrease of $\sim 20 \%$ in PLC $\beta-1$ immunoreactivity in the aged compared with the young animals (Table 2). Figure 5 shows that particulate PLC $\beta-1$ levels were

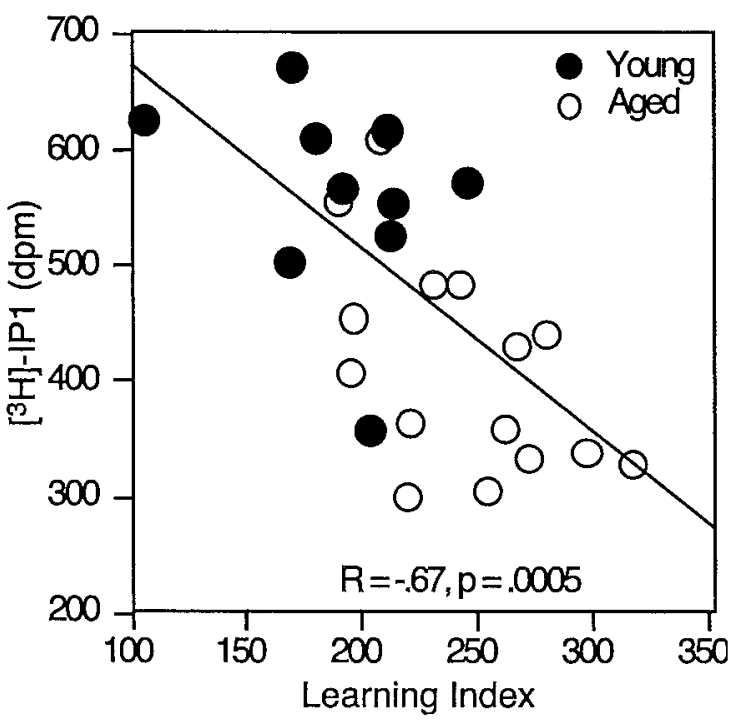

Figure 3. Maximal mGluR-mediated PI turnover plotted as a function of spatial learning ability. Individual data points for young and aged rats are shown for the 1S,3R ACPD $E_{\mathrm{MAX}}$. The solid line indicates the linear regression between PI turnover and learning index for young and aged animals grouped together.

significantly correlated with the learning index when young and aged rats were included in the regression analysis $(r=-0.36, p<$ $0.05)$. No significant relationship was observed, however, when the aged rats were considered alone $(r=-0.27, p=0.19)$.

\section{DISCUSSION}

The primary aim of this study was to determine whether deficits in muscarinic receptor-mediated PI turnover in the aged rat hippocampus found in a previous study (Chouinard et al., 1995) extended to mGluR-mediated PI turnover. This was indeed the case, because the $1 \mathrm{~S}, 3 \mathrm{R}$ ACPD $E_{\mathrm{MAx}}$ was decreased by $26 \%$ in the hippocampus of aged rats compared with young rats, a result that is similar in magnitude to that observed in response to stimulation with a muscarinic agonist. The change in the response to cholinergic stimulation occurred in the absence of decreased levels of the muscarinic receptor proteins $\mathrm{m} 1$ and $\mathrm{m} 3$, which couple to PI turnover (Chouinard et al., 1995). Similarly, the present study found no indication of a decline in the levels of metabotropic glutamate proteins mGluR-1 and mGluR-5 that are coupled to PI turnover. Taken together, these data provide consistent support for the concept that age-related alterations occur in the effector system of PI signal transduction and not at the level of receptor expression. Our examination of effector proteins in this transduction system, G $\alpha \mathrm{q} 11$ and PLC $\beta-1$, demonstrated that that G $\alpha$ q11 immunoreactivity did not change with age but that PLC $\beta-1$ immunoreactivity decreased by $\sim 20 \%$ in aged compared with young rats. These results suggest that a loss in PLC $\beta-1$ may contribute to the blunted PI turnover observed in response to stimulation of receptors for multiple transmitters in the aged hippocampus.

The functional measure of mGluR-mediated PI transduction in the current investigation was examined in relation to hippocampal-dependent spatial learning. Rats with the most blunted mGluR-mediated PI turnover were also those with the most severe spatial learning impairment $(r=-0.67, p<0.01)$. Using the same methods of behavioral characterization and measurement of the maximal PI response, we reported a significant 
A. mGluR-5

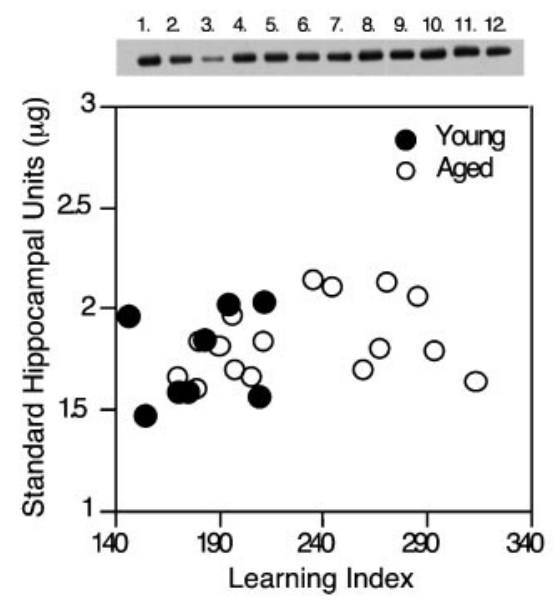

B. mGluR-1

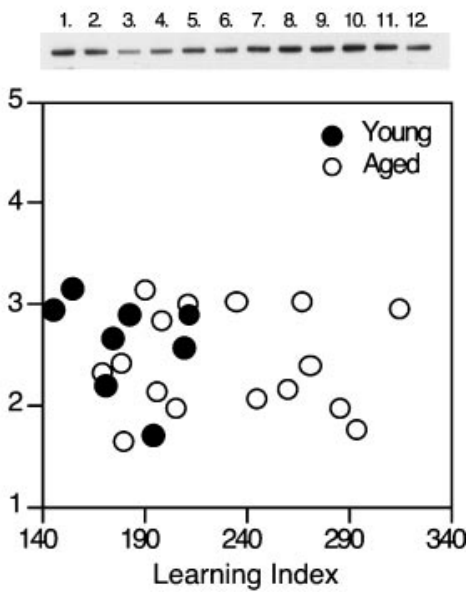

Figure 4. Immunoblot assays of mGluR-5 and mGluR-1. Representative Western blots are shown above each graph. The lanes numbered 1-3 mark the standard curve, with lane 1 containing the highest standard concentration. Lanes 4-11 contain samples from the young and aged Long-Evans rats, and lane 12 contains a replicate of lane 1 . The graphs show the levels of mGluR-5 $(A)$ or mGluR-1 $(B)$ immunoreactivity plotted against the learning index.

Table 2. Protein immunoreactivity levels in young and aged rats (microgram equivalent to standards \pm SEM)

\begin{tabular}{lrr} 
& \multicolumn{1}{c}{ Young } & \multicolumn{1}{c}{ Aged } \\
\hline mGluR-1 & $2.64 \pm 0.17$ & $2.44 \pm 0.12$ \\
mGluR-5 & $1.77 \pm 0.08$ & $1.85 \pm 0.05$ \\
G $\alpha \mathrm{q} 11$ & $14.26 \pm 0.88$ & $14.77 \pm 0.68$ \\
PLC $\beta-1^{*}$ & $10.29 \pm 0.65$ & $8.32 \pm 0.53$ \\
\hline
\end{tabular}

${ }^{*} p<0.05$.

correlation between blunted PI turnover mediated by oxotremorine-M and poor spatial learning among young and aged rats $(r=-0.82, p<0.001)$ (Chouinard et al., 1995). Comparable results, however, have not been obtained in all studies of aging on the PI transduction pathway (Tandon et al., 1991; Parent et al., 1995). Parent et al. (1995) found an enhanced hippocampal PI response in aged impaired Long-Evans rats, relative to unimpaired rats, to carbachol and trans-ACPD stimulation in hippocampus (Parent et al., 1995). Notably, Parent at al. (1995) also found a significant increase in basal PI turnover in aged rats with behavioral impairment, a finding that was not evident in our studies (Table 1). That discrepancy could be attributable to a number of factors that differed between the studies, including the ages of the groups compared, the method of selection of aged subjects in the analysis, housing conditions, and so forth (Tandon et al., 1991; Parent et al., 1995).

A number of lines of evidence using experimental treatments support the interpretation that the effect of aging on this signal transduction system contributes to cognitive impairment. Studies using pharmacological agents to block the function of mGluRs or muscarinic receptors have reported deficits in spatial learning in the Morris water maze (Whishaw, 1985; Bordi et al., 1996). In addition, mice with a targeted knockout of mGluR-5 are impaired in this same type of learning assessment (Lu et al., 1997). Other studies have shown that phosphoinositide-coupled mGluRs are necessary for long-term potentiation (LTP) in the dentate gyrus (Riedel and Reymann, 1993) and CA1 (Breakwell et al., 1996). A basis for this requirement may be provided by the ability of these receptors to both potentiate AMPA receptor-evoked responses (Sergueeva et al., 1993) and enhance the NMDA component of LTP induction (O'Connor et al., 1994). Finally, phosphoinositide signal transduction regulates protein synthesis via protein kinase C activation (Weiler and Greenough, 1993; Angenstein et al., 1998), a downstream effect in the cascade that is considered to be important for long-term modifications in the encoding of information by hippocampal neurons (cf. Ben-Ari et al., 1992).

The analysis of PI effector proteins in the current investigation provides a possible basis for a signaling defect in aged rats. To our knowledge no other published reports have examined the status
Figure 5. Immunoblot assays of G $\alpha \mathrm{q} 11$ and PLC $\beta-1$. Representative Western blots are shown above each graph. For $\mathrm{G} \alpha \mathrm{q} 11(A)$, the lanes numbered 1-5 mark the standard curve, with lane 5 containing the highest standard concentration and lane 6 containing a replicate of the lowest standard. Lanes 7-12 mark the samples from a subset of young and aged Long-Evans rats. For PLC $\beta-1(B)$, the lanes numbered 1-5 mark the standard curve, with lane 5 containing the highest standard concentration and lanes 6-12 containing the samples from the young and aged Long-Evans rats. The graphs show the levels of G $\alpha \mathrm{q} 11$ $(A)$ or PLC $\beta-1(B)$ immunoreactivity plotted against the learning index. The solid line in $B$ indicates the correlation for the young and aged animals considered together.
A. $\mathrm{G} \alpha \mathrm{q} / \mathbf{1 1}$

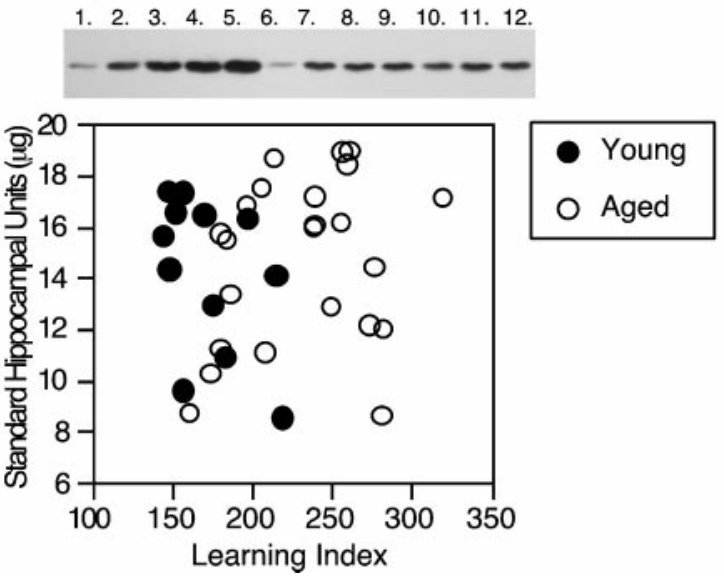

B. PLC $\beta-1$

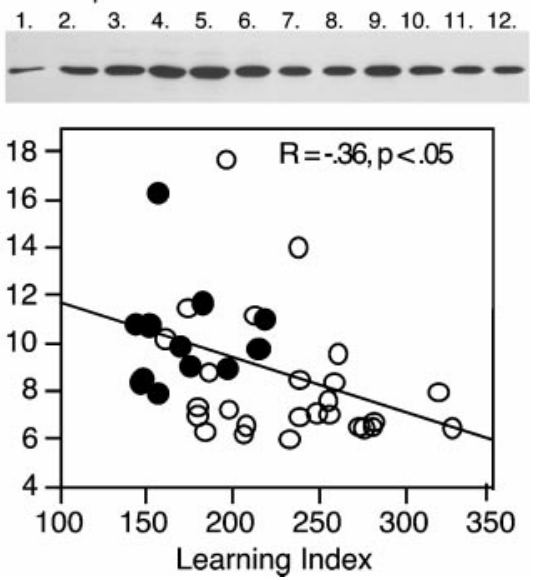


of $\mathrm{G} \alpha \mathrm{q} / 11$ in normal aging in the rodent. Our results indicate that protein levels of $\mathrm{G} \alpha \mathrm{q} / 11$ do not decline in the hippocampus with aging. By contrast, the level of PLC $\beta-1$ was significantly decreased in the hippocampus of the aged rats. This enzyme has been reported to be decreased in striatum and frontal cortex of aged Fisher 344 rats (Undie et al., 1995), but no previous studies appear to have examined protein levels in hippocampus. Our current finding may relate to age-related changes in posttranslational factors because mRNA levels for PLC $\beta$ were reportedly unchanged in the hippocampus of aged rats (Narang et al., 1996).

Based on the current findings, additional studies will be needed to determine whether the effects of aging on PLC $\beta-1$ are sufficient to account for diminished signal transduction in the PI pathway. Unlike the relationship between the measure of diminished PI response and behavioral impairment, which was correlated among the aged rats, PLC $\beta-1$ was associated with poorer spatial learning only when the young and aged rats were considered together in the correlation; this result suggests that lower PLC $\beta-1$ protein contributes to, but does not totally account for, the blunted PI turnover associated with age-related cognitive decline. Other factors that influence maximal PI turnover may be needed to fully explain the effect of aging on receptor-effector function. Measurement of PLC $\beta-1$ activity, for example, would reveal whether the aged rats with the most blunted PI turnover have less PLC $\beta-1$ activity, although the level of the protein is essentially uniformly reduced in the aged group regardless of behavioral performance. Additionally, it is unknown whether PLC $\beta-1$ has enough substrate to generate IP1. Indeed, there is some evidence of alterations in the kinases needed to create the PIP2 pool. In cerebral cortex, Bothmer et al. (1994) showed that there is an increase in PI kinase activity and a decrease in PIP kinase activity in 14- and 26-month-old Brown Norway rats compared with 8-month-old rats. Perhaps additional differences in such measures would contribute to the individual differences observed in the maximal PI response. Additionally, there is some evidence that protein kinase C can inhibit PI turnover (Ryu et al., 1990; Meldrum et al., 1991), and age-related spatial memory impairment in this study population is associated with increased concentrations of the calcium-sensitive PKC $\gamma$ (Colombo et al., 1997).

In summary, we provide evidence of an age-related deficit in PI signal transduction mediated by the mGluRs in the hippocampus. This deficit is independent of receptor expression. The absence of a decline in neurotransmitter receptor expression is consistent with evidence that neuron loss does not occur in the hippocampus, even in animals with documented cognitive deficits (Rapp and Gallagher, 1996; Rasmussen et al., 1996). The current results showed that the deficit in PI signal transduction is linked to a decrease observed in one component of the effector system PLC $\beta-1$. These findings, along with other studies of functional alterations in the hippocampus during aging (Shen and Barnes, 1996; Sugaya et al., 1996; Barnes et al., 1997; Colombo et al., 1997; Shen et al., 1997; Tanila et al., 1997a,b; Nicolle et al., 1999), suggest that age-related changes in signaling mechanisms in hippocampal circuitry may contribute substantially to cognitive decline.

\section{REFERENCES}

Angenstein F, Greenough WT, Weiler IJ (1998) Metabotropic glutamate receptor-initiated translocation of protein kinase p90rsk to polyribosomes: a possible factor regulating synaptic protein synthesis. Proc Natl Acad Sci USA 95:15078-15083.
Barnes CA, Suster MS, Shen JM, McNaughton BL (1997) Multistability of cognitive maps in the hippocampus of old rats. Nature 388:272-275.

Ben-Ari Y, Aniksztejn L, Bregestovski P (1992) Protein kinase C modulation of NMDA currents: an important link for LTP induction. Trends Neurosci 15:333-339.

Berstein G, Blank JL, Smrcka AV, Higashijima T, Sternweis PC, Exton JH, Ross EM (1992) Reconstitution of agonist-stimulated phosphatidylinositol 4,5-bisphosphate hydrolysis using purified $\mathrm{m} 1$ muscarinic receptor, $\mathrm{G}_{\mathrm{q} / 11}$, and phospholipase C- $\beta 1$. J Biol Chem 267:8081-8088.

Bordi F, Marcon C, Chiamulera C, Reggiani A (1996) Effects of the metabotropic glutamate receptor antagonist MCPG on spatial and context-specific learning. Neuropharmacology 35:1557-1565.

Bothmer J, Mommers M, Markerink M, Jolles J (1994) The effect of age on phosphatidylinositol kinase, phosphatidylinositol phosphate kinase and diacylglycerol kinase activities in rat brain cortex. Growth Dev Aging 58:67-73.

Bradford MM (1976) A rapid and sensitive method for the quantitation of microgram quantities of protein utilizing the principle of protein-dye binding. Anal Biochem 72:248-254.

Breakwell NA, Rowan MJ, Anwyl R (1996) Metabotropic glutamate receptor dependent EPSP and EPSP-spike potentiation in area CA1 of the submerged rat hippocampal slice. J Neurophysiol 76:3126-3135.

Chouinard ML, Gallagher M, Yasuda RP, Wolfe BB, McKinney M (1995) Hippocampal muscarinic receptor function in spatial learningimpaired aged rats. Neurobiol Aging 16:955-963.

Colombo PJ, Wetsel WC, Gallagher M (1997) Spatial memory is related to hippocampal subcellular concentrations of calcium-dependent protein kinase $\mathrm{C}$ isoforms in young and aged rats. Proc Natl Acad Sci USA 94:14195-14199.

Fisher S, Bartus RT (1985) Regional differences in the coupling of muscarinic receptors to inositol phospholipid hydrolysis in guinea pig brain. J Neurochem 45:1085-1095.

Gallagher M, Burwell R, Burchinal M (1993) Severity of spatial learning impairment in aging: development of a learning index for performance in the Morris water maze. Behav Neurosci 107:618-626.

Gu DW, Wolfe BB (1985) Pirenzepine distinguishes between muscarinic receptor-mediated phosphoinositide breakdown and inhibition of adenylate cyclase. J Pharmacol Exp Ther 232:608-616.

Kim CG, Park D, Rhee SG (1996) The role of carboxyl-terminal basic amino acids in $\mathrm{Gq} \alpha$-dependent activation, particulate association, and nuclear localization of phospholipase C- $\beta 1$. J Biol Chem 271:21187-21192.

Kostenis E, Degtyarev MY, Conlin BR, Wess J (1997) The N-terminal extension of $\mathrm{G} \alpha \mathrm{q}$ is critical for constraining the selectivity of receptor coupling. J Biol Chem 272:19107-19110.

Lu YM, Jia Z, Janus C, Henderson JT, Gerlai R, Wojtowicz JM, Roder JC (1997) Mice lacking metabotropic glutamate receptor 5 show impaired learning and reduced CA1 long-term potentiation (LTP) but normal CA3 LTP. J Neurosci 17:5196-5205.

Lujan R, Nusser Z, Roberts J, Shigemoto R, Somogyi P (1996) Perisynaptic location of metabotropic glutamate receptors mGluR1 and mGluR5 on dendrites and dendritic spines in the rat hippocampus. Eur J Neurosci 8:1488-1500.

McKinney M, Anderson D, Vella-Roundtree L, Connolly T, Miller JH (1991) Pharmacological profiles for rat cortical M1 and M2 muscarinic receptors using selective antagonists: comparison with N1E-115 muscarinic receptors. J Pharmacol Exp Ther 257:1121-1129.

Meldrum E, Parker PJ, Carozzi A (1991) The PtdIns-PLC superfamily and signal transduction. Biochim Biophys Acta 1092:49-71.

Narang N, Joseph J, Ayyagari P, Gerber M, Crews F (1996) Age-related loss of cholinergic-muscarinic coupling to PLC: comparison with changes in brain regional PLC subtypes mRNA distribution. Brain Res 708:143-152.

Nicolle MM, Gallagher M, McKinney M (1999) No loss of synaptic proteins in the hippocampus of aged, behaviorally-impaired rats. Neurobiol Aging, in press.

O'Connor JJ, Rowan MJ, Anwyl R (1994) Long-lasting enhancement of NMDA receptor-mediated synaptic transmission by metabotropic glutamate receptor activation. Nature 367:557-559.

Parent A, Rowe W, Meaney MJ, Quirion R (1995) Increased production of inositol phosphates and diacylglycerol in aged cognitively impaired rats after stimulation of muscarinic, metabotropic-glutamate and endothelin receptors. J Pharmacol Exp Ther 272:1110-1116.

Rapp PR, Gallagher M (1996) Preserved neuron number in the hip- 
pocampus of aged rats with spatial learning deficits. Proc Natl Acad Sci USA 93:9926-9930.

Rasmussen T, Schliemann T, Sorensen JC, Zimmer J, West M (1996) Memory impaired aged rats: no loss of principle hippocampal and subicular neurons. Neurobiol Aging 17:143-147.

Riedel G, Reymann K (1993) An antagonist of the metabotropic glutamate receptor prevents LTP in the dentate gyrus of freely moving rats. Neuropharmacology 32:929-931.

Rouse ST, Levey AI (1996) Expression of m1-m4 muscarinic acetylcholine receptor immunoreactivity in septohippocampal neurons and other identified hippocampal afferents. J Comp Neurol 375:406-416.

Ryu SH, Kim UH, Wahl MI, Brown AB, Carpenter G, Huang KP, Rhee SG (1990) Feedback regulation of phospholipase C-beta by protein kinase C. J Biol Chem 265:17941-17945.

Schoepp DD (1994) Novel functions for subtypes of metabotropic glutamate receptors. Neurochem Internat 24:439-449.

Sergueeva OA, Fedorov NB, Reymann KG (1993) An antagonist of glutamate metabotropic receptors, (RS)-alpha-methyl-4-carboxyphenylglycine, prevents the LTP-related increase in postsynaptic AMPA sensitivity in hippocampal slices. Neuropharmacology 32:933-935.

Shen J, Barnes CA (1996) Age-related decrease in cholinergic synaptic transmission in three hippocampal subfields. Neurobiol Aging $17: 439-451$.

Shen J, Barnes CA, McNaughton BL, Skaggs WE, Weaver KL (1997) The effect of aging on experience-dependent plasticity of hippocampal place cells. J Neurosci 17:6769-6782.

Smrcka AV, Hepler JR, Brown KO, Sternweis PC (1991) Regulation of polyphosphoinositide-specific phospholipase $\mathrm{C}$ activity by purified $\mathrm{Gq}$. Science 251:804-807.
Sugaya K, Chouinard M, Greene R, Robbins M, Personett D, Kent C, Gallagher M, McKinney M (1996) Molecular indices of neuronal and glial plasticity in the hippocampal formation in a rodent model of age-induced spatial learning impairment. J Neurosci 16:3427-3443.

Tandon P, Mundy WR, Ali SF, Nanry K, Rogers BC, Tilson HA (1991) Age-dependent changes in receptor-stimulated phosphoinositide turnover in the rat hippocampus. Pharmacol Biochem Behav 38:861-867.

Tanila H, Shapiro M, Gallagher M, Eichenbaum H (1997a) Brain aging: changes in the nature of information coding by the hippocampus. J Neurosci 17:5155-5166.

Tanila H, Sipila P, Shapiro M, Eichenbaum H (1997b) Brain aging: impaired coding of novel environmental cues. J Neurosci 17:5167-5174.

Taylor SJ, Chae HZ, Rhee SG, Exton JH (1991) Activation of the $\beta 1$ isozyme of phospholipase $\mathrm{C}$ by $\alpha$ subunits of the Gq class of $\mathrm{G}$ proteins. Nature 350:516-518.

Undie A, Wang H-Y, Friedman E (1995) Decreased phospholipase C- $\beta$ immunoreactivity, phosphoinositide metabolism, and protein kinase $\mathrm{C}$ activation in senescent F-344 rat brain. Neurobiol Aging 16:19-28.

Weiler IJ, Greenough WT (1993) Metabotropic glutamate receptors trigger postsynaptic protein synthesis. Proc Natl Acad Sci USA 90:7168-7171.

Wetsel WC, Khan WA, Merchenthaler I, Rivera H, Halpern AE, Phung HM, Negro-Vilar A, Hannun YA (1992) Tissue and cellular distribution of the extended family of protein kinase C isoenzymes. J Cell Biol 117:121-133.

Whishaw IQ (1985) Cholinergic receptor blockade in the rat impairs locale but not taxon strategies for place navigation in a swimming pool. Behav Neurosci 99:979-1005. 